\title{
Vorbemerkung
}

\section{zu Gegenstand, Methode und Ergebnis der Untersuchung}

Die Arbeit untersucht die dogmengeschichtlichen Grundlagen des Bestandteils- und Zubehörbegriffs des geltenden deutschen Rechts. Sie findet sie im gemeinrechtlichen Pertinenzbegriff in der Ausprägung, den dieser seit dem Ende des 18. Jahrhunderts durch die Naturrechtskodifikationen und durch die Jurisprudenz des 19. Jahrhunderts erfahren hat.

Obwohl Thema und Zielsetzung der Untersuchung danach primär historisch sind und ihr zeitlicher Schwerpunkt das 19. Jahrhundert ist, verbindet der Verfasser mit ihr zugleich ein methodisches und dogmatisches Anliegen, das schon im ersten, römischrechtlichen Teil sichtbar wird, der hierdurch zum Schlüssel für das Verständnis der folgenden Ausführungen wird. Sein methodischer Versuch besteht in dem Wagnis, die empirische Bestandsaufnahme eines konkret gegebenen Rechts - hier des klassisch römischen - mit einer Interpretation zu verbinden, die den historischen Befund in ein apriorisches dogmatisches Strukturschema übersetzt und als Verwirklichung eines von mehreren möglichen Modellen begreiflich macht. Er glaubt, dadurch zugleich einen Beitrag zur heutigen Dogmatik vom Rechtsobjekt geleistet zu haben, als einer Dogmatik, deren Kategoriengewinn einem historischen Erkenntnisprozeß zu verdanken ist, der sich am gelehrten Umgang mit jenem selben geschichtlichen Recht - dem römischen - vollzogen hat.

Die dargestellte dogmengeschichtliche Entwicklung scheint dem Verfasser für den historischen Aspekt insofern von allgemeinerem Interesse zu sein, als in ihr am Beispiel eines einzelnen Rechtsbegriffs die Mühen des Weges sichtbar werden, den die dem Text des Corpus iuris verpflichtete, der Unbefangenheit des Usus modernus entwachsene Pandektistik hat gehen müssen, um das überlieferte vorindustrielle Recht den neuen Erfordernissen der hochkapitalistischen Industriewirtschaft anzupassen: d. h. in unserem Falle, dem Sicherungsbedürfnis des Betriebskredits ein praktikables, tragfähiges Haftungsabjekt anzubieten. Innerhalb des sehr breiten Spektrums von Reaktionsweisen der Pandektenwissenschaft auf die industrielle Revolution ist die 
Geschichte des Pertinenbegriffs daher einer der Fälle, in denen „die Quellen und die Auslegung, die ihnen der logische Formalismus gegeben hatte, in entschiedenem Widerspruch zu den Zeitbedürfnissen stehen ", und in denen „die Anpassung an die Wirklichkeit erst spät und mühsam, meist erst bei der Redaktion des BGB, endgültig sich durchsetzt", wie Wieacker in seinem Aufsatz über „Pandektenwissenschaft und industrielle Revolution“ (JuristenJahrbuch, Band 9 [Köln 1969], 1 ff. [13]) es jüngst formuliert hat. 